\section{The addition of enteral to parenteral antimicrobials may prolong antibiotic era}

HENDRIK K.F. VAN SAENE • NIA TAYLOR • SMILJA KALENIĆ • MLADEN PERIĆ • MIGUEL ANGEL DE LA CAL
HENDRIK K.F. VAN SAENE $(\bowtie) \bullet$ NIA TAYLOR School of Clinical Sciences University of Liverpool Duncan Building Daulby Street Liverpool L69 3GA, UK Phone: +44151706 4932 Fax: +441517065803 E-mail: nia.taylor@liv.ac.uk

SMILJA KALENIĆ

Department of Clinical and

Molecular Microbiology Clinical Hospital Centre Zagreb Kispatičeva 12, 10000 Zagreb, Croatia

MLADEN PERIĆ

Department of Anaesthesiology and Intensive Care, Clinical Hospital

Centre Zagreb

Kispatičeva 12, 10000 Zagreb, Croatia

MIGUEL ANGEL DE LA CAL

Department of Intensive Care

University Hospital Getafe, Madrid, Spain

\begin{abstract}
Resistance to parenteral antimicrobials generally occurs within two years after introduction into general use. The site where de novo resistance develops has been acknowledged to be the gut. Overgrowth of abnormal flora, defined as $10^{5}$ potential pathogens per $\mathrm{g}$ of faeces is a risk factor for resistance following increased spontaneous mutation leading to polyclonality and antimic robial resistance. As parenteral antimicrobials generally fail to eradicate the abnormal carrier state in overg rowth concentrations due to sub-lethal concentrations in bile and mucus the enteral antimicrobials polymyxin/tobramycin aiming at converting the abnormal carrier state into normal carriage, are the essential component of selective decontamination of the digestive tract (SDD), because they eradicate carriage and overgrowth including resistant mutants, maintaining the usefulness of parenteral antimicrobials.
\end{abstract}

Keywords: normal carriage, abnormal carriage, overgrowth, mutation, polyclonality, resistance, selective decontamination of the digestive tract, parenteral antimicrobials, enteral antimicrobials

\section{Introduction}

Underlying disease determines abnormal carriage, and the abnormal carrier state, in particular of the gut, is the main risk factor for the emergence of antimicrobial resistance. (1) For example, only diseased individuals carry potenti- ally pathogenic micro-organisms (PPM) such as Pseudomonas aeruginosa in overgrowth concentrations, ie. $\geq 10^{5}$ abnormal bacteria per $g$ of faeces. Intravenous ceftazidime induces increased spontaneous mutation, polyclonality and antibiotic resistance. (2) Selective decontamination of the digestive tract (SDD) aims to convert the abnormal carrier state in overgrowth concentrations into normal carriage, therefore preventing the emergence of antimicrobial resistance. (3)

The many years, over 20 , of clinical
SDD research yielding 57 randomised controlled trials (RCTs) demonstrated an intriguing finding that SDD does not increase the problem of antimicrobial resistance but reduces the problem. (4) Two $(5,6)$ of the 57 RCTs, report an increase in resistance. Interestingly, the endpoint was the number of resistant isolates, not patients, in these two RCTs.

Three RCTs evaluated the impact of SDD on the number of patients who carried antibiotic resistant aerobic Gram-negative bacilli (AGNB). (7-9) 
A Klebsiella pneumoniae producing extended-spectrum beta-lactamase (ESBL) was endemic in a French hospital (7): carriage and infection rates were $19.6 \%$ and $9 \%$, respectively. Once enteral antimicrobials were added to the parenteral, there was a significant reduction in both carriage and infection (19.6\% versus $1 \%$; $9 \%$ versus $0 \%$ ). (7) A Dutch mono-centre RCT including 1,000 patients reports that carriage of AGNB resistant to imipenem, ceftazidime, ciprofloxacin, tobramycin and polymyxins occurred in $16 \%$ of patients receiving parenteral and enteral antimicrobials, compared to $26 \%$ of control patients receiving only parenteral anticiotics with a relative risk of $0.6(95 \% \mathrm{Cl}$ 0.5-0.8). (8)

The largest multi-centre RCT to date, also from the Netherlands, includes 6,000 patients, and the proportion of patients with Gram-negative bacteria in rectal swabs that were not susceptible to the marker antibiotics was lower with SDD than with standard care or selective oropharyngeal decontamination (SOD), a modified SDD protocol without the gut component. For example, carriage of multi-resistant $P$.aeruginosa was $0.4 \%$ in SDD versus $0.8 \%$ in SOD and $1.3 \%$ in the group receiving standard care $(p<0.005)$. (9)

The traditional approach is based on two pillars, restriction of parenteral antibiotics and transmission control using hand washing and isolation.

\section{Restriction of solely paren- teral antimicrobials}

There is evidence relating antimicrobial usage to emerging resistance. (10) Generally, carriage in the throat and gut, and colonisation of internal organs by PPM, are not treated. Only infection is treated (parenterally) to limit the use of systemic antibiotics. Despite widespread attempts to limit the use of systemic antibiotics, over $70 \%$ of all patients who stay over three days on the intensive care unit (ICU) will receive them. (11) There are two approaches to controlling antibiotic usage. These include increasing the specificity of the diagnosis of pneumonia, $30 \%$ of all infections, by invasive techniques, and scheduled changes of antibiotic classes.

The 'pneumonia' rate is halved using invasive strategies compared with non-invasive methods. (12) Two randomised trials have demonstrated that diagnosing pneumonia less frequently in this fashion is not associated with a reduction in mortality. $(13,14)$ A French randomised trial of 413 patients compared 204 patients managed invasively with protected brush specimens with 209 patients managed non-invasively with tracheal aspirates. (13) They failed to show any survival benefit at 28 days $(30.9 \%$ versus $28.8 \%, p=0.10$ ) using restrictive antibiotic prescribing policies. A Spanish randomised trial of 77 patients, comparing an invasive diagnostic approach $(n=38)$, found that the 30 day outcome of pneumonia was not influenced (38\% versus $46 \%$, $p=0.46$ ) by the techniques used for microbial investigation. (14) Additionally, both trials evaluated the emergence of antimicrobial resistance as a secondary endpoint. In the French trial the proportions of resistant isolates obtained from lower airway secretions were similar in both invasive (61.3\%) and non-invasive $(59.8 \%)$ groups, despite significantly less use of antibiotics in the invasive group. The Spanish trial reported identical high isolation rates of $58.3 \%$ of resistant bacteria, methicillin-resistant Staphylococcus aureus (MRSA) and Pseudomonas aeruginosa in both groups.

Strategies that recommend manipulating in-hospital antibiotic use have been suggested, in order to reduce possible emergence of resistance in critically ill patients. One such strategy is to schedule a rotation of antibiotics. This strategy entails a regimented preference for a specific antibiotic in a given environment over a fixed period, after which preference is switched to an alternative agent with a similar spectrum of activity. The assumption underlying this strategy is that the exposure to each antibiotic in the schedule is sufficiently short to preclude the emergence of significant populations of micro-organisms resistant to any one of them.
The evidence to support this recommendation is sparse and the data are conflicting. $(15,16)$ In a cardiac ICU, six months of ceftazidime administration was followed by six months of ciprofloxacin administration and a comparison was made. (15) Although not true cycling (the prior regimen was not reused, therefore the effect of a full cycle was not tested), this study suggested that scheduled changes in classes of antibiotics may reduce infection with resistant $A G N B$. There was a significant reduction in the incidence of pneumonia due to resistant AGNB (4\% versus $0.9 \% p=0.013)$. The non-randomised design is a fundamental flaw confirmed by the difference in the etiology of the causative agents. During ceftazidime treatment there was an outbreak of intrinsically resistant Serratia (7 pneumonias), additionally there were five viral and three Aspergillus pneumonias, ie. 15 of 41 pneumonias were inappropriately treated by ceftazidime. During ciprofloxacin treatment there were 22 pneumonias in total, only one of which was viral. The difference in pneumonia is no longer significant when comparing the appropriately treated pneumonias, ie. 26 and 21.

In a neonatal ICU, a monthly rotation of gentamicin, piperacillin-tazobactam, and ceftazidime was compared with unrestricted antibiotic use between two geographically separated teams (rotation versus control team). (16) In total, $10.7 \%$ of infants on the rotation team versus $7.7 \%$ on the control team carried resistant $A G N B$ in the throat and gut. There was no difference in the incidence of infections, morbidity, and mortality.

Proponents and antagonists of antibiotic cycling agree that there are many difficult and complex methodological issues, surrounding the use of antibiotic cycling.

Factors potentially determining the effectiveness of antibiotic cycling include endemic rates of carriage with particular AGNB and their mechanisms of antibiotic resistance, the transmission dynamics of particular AGNB in a specific unit, the population dynamics of the 
unit staff, the composition and duration of the antibiotic regimens, compliance with antibiotic cycling, and concurrent infection control practices to limit transmission of resistant AGNB. There is limited information on which to base decisions of how long each antibiotic regimen should be used and how many regimens should be cycled.

\section{Control of transmission of resistant micro-organisms via hands of carers}

The endpoint of traditional infection control is the control of infection due to the control of transmission of resistant micro-organisms via hands of carers. The two main manoeuvres are isolation (17) and hand washing. (18) A recent two-centre prospective crossover study from the United Kingdom, demonstrated that placing patients who are treated in ICU and who carry MRSA or who are infected by MRSA in single rooms or cohorting them in a multi-bed bay when a single room was not available, had no effect on transmission of MRSA when combined with what the investigators term "standard" (17) precautions for all patients treated on ICU.

The experts tried to explain this negative study by the poor adherence to hand hygiene, the hand washing compliance rate was $21 \%$ in the study. (19) A recent systematic review of hand washing suggests that hand washing does not abolish but only reduces transmission of potential pathogens by lowering the contamination level of hands. (18) The policy of sole use of parenteral antimicrobials has failed to control resistance. Generally, resistance to a new antibiotic emerges within two years of general use. $(20,21)$ We believe that this experience is due to the common denominator of ignoring the gut in all four manoeuvres of restricted antibiotic use, cycling of antibiotics, isolation and hand washing. The major source of the gut is left intact allowing resistant mutants to emerge and to cause superinfections and subsequent outbreaks. There are four long-term studies ( $\geq 2$ years) evaluating the impact of polymyxin/tobramycin on resistance amongst AGNB. (22-25)

The resistance data of the long-term studies confirm the RCT findings that rates of carriage and infection due to resistant $A G N B$ in patients receiving enteral and parenteral antimicrobials are not increased but actually lower compared with patients receiving solely parenteral antimicrobials.
Most patients who require long-term treatment on ICU have overgrowth of abnormal flora defined as $10^{5}$ AGNB per $\mathrm{ml}$ of saliva and/or per $\mathrm{g}$ of faeces. Gut overgrowth guarantees increased spontaneous mutation, leading to polyclonality and antimicrobial resistance. (2) As parenteral antimicrobials generally fail to eradicate the abnormal carrier state in overgrowth concentrations, the enteral antimicrobials polymyxin/ tobramycin aiming at converting the abnormal carrier state into normal carriage, is the essential component of SDD, because they eradicate carriage and overgrowth of AGNB including resistant mutants, maintaining the usefulness of parenteral antimicrobials.

Approximately one third of patients requiring treatment on ICU, import resistant micro-organisms in their admission flora, about one third acquire resistant micro-organisms following transmission via hands of carers, and the last third develop de novo resistance due to mutation following gut overgrowth.

SDD using enteral polymyxin/tobramycin with or without vancomycin prevents acquisition and de novo development in eradicating abnormal flora of resistant bacteria present in the admission flora.

\section{REFERENCES}

1. van Saene HKF, Zandstra DF. Selective decontamination of the digestive tract: rationale behind evidence-based use in liver transplantation. Liver Transpl 2004;10:828-33.

2. van Saene HKF, Taylor N, Damjanovic V, Sarginson RE. Microbial gut overgrowth guarantees increased spontaneous mutation leading to polyclonality and antibiotic resistance in the critically ill. Curr Drug Targ 2008;9:419-21.

3. Silvestri L, van Saene HKF, Casarin A, Berlot G, Gullo A. Impact of selective decontamination of the digestive tract on carriage and infection due to Gram-negative and Gram-positive bacteria: a systematic review of randomised controlled trials. Anaesth Inten Care 2008;36:324-38.

4. Silvestri $L$, van Saene HKF. Selective decontamination of the digestive tract does not increase resistance in critically ill patients: evidence from randomized controlled trials. Crit Care Med 2006;34:2027-30

5. Rocha LA, Martin MJ, Pita S, Paz J, Seco C, Margusino L, et al. Prevention of nosocomial infection in critically ill patients by selective decontamination of the digestive tract. Inten Care Med 1992;18:398-404.

6. Verwaest C, Verhaegen J, Ferdinande P, Schetz M, Van den Berghe G, Verbist L, et al. Randomized controlled trial of selective digestive decontamination in 600 mechanically ventilated patients in a multi-disciplinary intensive care unit. Crit Care Med 1997;25:63-71.

7. Brun-Buisson C, Legrand P, Rauss AA, Richard C, Montravers F, Besbes M, et al. Intestinal decontamination for control of nosocomial multi-resistant Gram-negative bacilli. Ann Intern Med 1989;110:873-81.

8. de Jonge E, Schultz M, Spanjaard L, Bossuyt PM, Vroom MB, Dankert J, et al. Effects of selective decontamination of the digestive tract on mortality and acquisition of resistant bacteria in intensive care: a randomised, controlled trial. Lancet 2003;363:1101-16. 
9. de Smet AMGA, Kluytmans JAJW, Cooper BS, Mascini EM, Benus RF, van der Werf TS, et al. Decontamination of the digestive tract and oropharynx in ICU-patients. N Engl J Med 2009;360:20-31.

10. O'Grady NP, Salgado CD, Farr BM. Selective decontamination of the digestive tract does not increase resistance in critically ill patients: Evidence from randomized controlled trials. Crit Care Med 2006;34:2027-38.

11. Rangel Frausto MS, Pittet D, Costigan M, Hwang T, Davis CS, Wenzel RP. The natural history of the systemic inflammatory response syndrome (SIRS): a prospective study. JAMA 1995;273:117-23.

12. Cook D, Guyatt G, Marshall J, Leasa D, Fuller H, Hall R, et al. A comparison of sucralfate and ranitidine for the prevention of upper gastrointestinal bleeding in patients requiring mechanical ventilation. N Engl J Med 1998;338: 791-7.

13. Fagon JY, Chastre J, Wolff M, Gervais C, Parer Aubas S, Stéphan F, et al. Invasive and non-invasive strategies for management of suspected ventilator-associated pneumonia. A randomised trial. Ann Intern Med 2000;132:621-30.

14. Ruiz M, Torres A, Ewig S, Marcos MA, Alcón A, Lledó R, et al. Non-invasive versus invasive microbial investigation in ventilator-associated pneumonia: evaluation of outcome. Am J Respir Crit Care Med 2000;162:119-25.

15. Kollef MH, Vlasnik J, Sharpless L, Pasque C, Murphy D, Fraser V. Scheduled changes of antibiotic classes. A strategy to decrease the incidence of ventilator-associated pneumonia. Am J Respir Crit Care Med 1997;156:1040-8.

16. Toltzis P, Dul MJ, Hoyen C, Salvator A, Walsh M, Zetts L, et al. The effect of antibiotic rotation on colonization with antibiotic-resistant bacilli in a neonatal intensive care unit. Pediatrics 2002;110:707-11.

17. Cepeda JA, Whitehouse T, Cooper B, Hails J, Jones K, Kwaku F, et al. Isolation of patients in single rooms or cohorts to reduce spread of MRSA in intensive care units: prospective two-centre study. Lancet 2005;365:295-304.

18. Silvestri L, Petros AJ, Sarginson RE, de la Cal MA, Murray AE, van Saene HK. Hand washing in the intensive care unit: a big measure with modest effects. J Hosp Infect 2005;59:172-9.

19. Huskins WC, Goldmann DA. Controlling methicillin-resistant Staphylococcus aureus, aka žSuperbug'. Lancet 2005;365:273-5.

20. de Man P, Verhoeven BA, Verburgh HA, Vos MC, van den Anker JN. An antibiotic policy to prevent emergence of resistant bacilli. Lancet 2000;355:973-8.

21. Sompolinsky D, Yaron V, Alkan WJ. Microbiological changes in the human fecal flora following the administration of tetracyclines and chloramphenicol. The Am J Proctol 1967;18:471-8.

22. Stoutenbeek CP, van Saene HKF, Zandstra DF. The effect of oral non-absorbable antibiotics on the emergence of resistant bacteria in patients in an intensive care unit. J Antimicrob Chemother 1987;19:513-20

23. Leone M, Albanese J, Antonini F, Nguyen-Michel A, Martin C. Long-term (6 year) effect of selective digestive decontamination on antimicrobial resistance in intensive care, multiple-trauma patients. Crit Care Med 2003;31:2090-5.

24. Sarginson RE, Taylor N, Reilly N, Baines PB, van Saene HKF. Infection in prolonged paediatric critical illness: A prospective four-year study based on knowledge of the carrier state. Crit Care Med 2004;32:839-47.

25. Heininger A, Meyer E, Schwab F, Marschal M, Unertl K, Krueger WA. Effects of long-term routine use of selective decontamination on antimicrobial resistance. Inten Care Med 2006;32:1569-76. 